ORIGINAL ARTICLE

\title{
Cord Care Methods in Neonates
}

ANDLEEB KANWAL ${ }^{1}$, ZAHID ANWAR ${ }^{2}$, MATEEN AKRAM ${ }^{3}$, SHAHID ANWAR $^{4}$, SAIMA PIRZADA $^{5}$

${ }^{1}$ Senior Registrar Gynae \& Obs, Fatima Memorial Hospital, Lahore

${ }^{2}$ Assistant Professor Paeds department, Fatima Memorial Hospital, Lahore

${ }^{3}$ Assistant Professor Nephrology, Shaikh Zayed Hospital, Lahore

${ }^{4}$ Associate Professor Nephrology, Fatima Jinnah Medical University, Lahore

${ }^{5}$ Senior Registrar Paeds department, Fatima Memorial Hospital, Lahore

Corresponding author: Andleeb Kanwal, Email: sana755@hotmail.com, Cell: +92 3336118211

\begin{abstract}
Background: Proper cord care methods in neonates have been known to reduce infections, sepsis, and death. This study intends to document the frequency of cord care methods.

Methods: A questionnaire-based study was done in 6 months in a tertiary care hospital with a level 3 nursery and NICU (Fatima Memorial Hospital, Lahore). We interviewed mothers and female companions of neonates in wards and outpatient clinics. Answers were added to SPSS in socio-demographic categories and cord care methods.

Result: A total of 778 females were interviewed. The mean age is $28+8.1$ years, mostly educated $(90 \%)$ and resided in urban areas (83\%). $39.4 \%$ of the participants had personal experience of newborn care. Most were housewives $(74.4 \%)$.

$36.8 \%$ would not apply anything to the cord, but the other majority would apply some agent to the newborn cord, methylated spirit being the favourite (48.5\%), remaining being mostly antibiotics and antimicrobial agents. Chlorhexidine was used only by one participant.

Doctors and nurses had counselled $70 \%$ of the participants, but $10 \%$ listened to the advice of relatives and grandmothers. $18.5 \%$ declined any knowledge of safe practices.

Conclusions: Our study emphasizes the need to educate our hospital staff (doctors, nurses and midwives) as well as family members of neonates with standardised cord care methods.

Keywords: Neonates, Cord care, Umbilical cord,Methylated spirit.
\end{abstract}

\section{INTRODUCTION}

Sustainable Development Goals aim to reduce neonatal mortality to 12 per 1,000 live births and under-5 mortality to 25 per 1,000 live births(1). Pakistan still ranks second-highest in the world with a Neonatal mortality rate of (41.2 per 1000 live births), in 2019(2)(3).

Clean Birthing Process is a concept comprising of 6 hygienic practices, which are clean hands of the birth attendant, clean delivery surface, clean perineum, clean instrument to cut the cord, clean cord tie, and clean cord care (4). It has proven to reduce perinatal and neonatal infections(5). Another way to emphasize it is the incidence of cord infections (0.7\%) in developed and 8-22 \% in developing countries, ultimately leading to sepsis and mortality (6)(7).

World Health Organization (WHO) recommends "Daily chlorhexidine $(7.1 \%$ chlorhexidine digluconate aqueous solution or gel, delivering $4 \%$ chlorhexidine) application to the umbilical stump during the first week of life, for home deliveries especially in regions with high neonatal mortality (30 or more neonatal deaths per 1,000 live births). Clean and dry cord care is recommended for newborns born in health facilities or born at home in areas with low neonatal mortality. In low-risk areas, chlorhexidine is recommended only if there is tradition or risk of harmful methods such as application of cow dung (8).

Objective: This study aims to document the frequency of different methods in our hospital and their relation to different social (demographic)factors.

\section{MATETRIAL AND METHODS}

Fatima Memorial Hospital, Lahore is a teaching and tertiary care hospital, with well-established and busy obstetric and neonatal units. The study was conducted over 1 year fromJuly-2020 to December 2020.

The approximate sample size was 700 interviews, keeping the confidence interval at $99 \%$ ( $z$ value $=2.57$ ), error of margin at $3 \%$, and assumed prevalent poor cord care practices at $80 \%$, according to a previous study from Lahore. Sampling was done by non-probability convenient technique.

Participating doctors were trained about the questionnaire. They interviewed mothers and their female attendants, during ward rounds in obstetrics and neonatology as well as in neonatal outpatient rooms. Unmarried women were excluded from the study because of the traditional reluctance to answer the questions.
Verbal consent was taken. The anonymity of data was ensured.SPSS version 20 was used, descriptive parameters were expressed as frequency and percentages. A Chi-square test was used to identify any significant association between methods of cord care with age, parity, education, occupation and area of residence.

\section{RESULTS}

A total of 778 females were interviewed in 6 months. The mean age was $28+8.1$ years. The socio-demographic characteristics of participants are shown in table 1.

Table 1: Socio-Demographic Characteristics of Participants

\begin{tabular}{|l|l|l|}
\hline Variable & Frequency $(\mathrm{n})$ & Percentage (\%) \\
\hline Age & 11 & 1.41 \\
\hline 20 or less & 422 & 54.24 \\
\hline $21-30$ years & 234 & 30.08 \\
\hline $31-40$ years & 102 & 13.11 \\
\hline $41-50$ years & 9 & 1.16 \\
\hline$>50$ years \\
\hline Educational Status & 55.53 \\
\hline 10 or more years & 432 & 34.32 \\
\hline Less than 10 years & 267 & 10.15 \\
\hline Nil & 79 & 11.5 \\
\hline Marital Status & 20.4 \\
\hline Married but No Kid & 357 & 25.3 \\
\hline Married and First baby & 637 & 14.1 \\
\hline Married and 2nd baby & 788 & 56.81 \\
\hline Married and $>2$ kids & 438 & 16.97 \\
\hline Residence & 442 & 23.14 \\
\hline Lahore & 132 & 3.08 \\
\hline Villages & 180 & 74.42 \\
\hline Other Cities & 24 & 25.58 \\
\hline Outside Pakistan & 579 & \\
\hline Occupation & 199 & \\
\hline Housewives & \\
\hline Jobs/careers &
\end{tabular}

Most of our participants belonged to urban areas (83\%), were educated (illiterate only $10 \%$ ) and were housewives (74.4\%). $31.9 \%$ of females (married but no child + new mothers) previously had no personal experience of neonatal care. They were likely telling the practice that they had observed in the family.

The preferred methods of cord care are shown in Table 2. 
Table 2: Attitudes about Cord Care in Newborns

\begin{tabular}{|l|l|l|}
\hline Variable & $\begin{array}{l}\text { Frequency (n) Total }= \\
3115\end{array}$ & Percentage (\%) \\
\hline Source of Knowledge & 488 & 62.72 \\
\hline Doctor & 144 & 18.51 \\
\hline Do not Know & 60 & 7.71 \\
\hline relative/other & 55 & 7.07 \\
\hline Nurses/Midwives & 31 & 3.98 \\
\hline Grandmother & 377 & \\
\hline Method of Cleaning Cord & \multicolumn{2}{|l|}{} \\
\hline Spirit & 189 & 48.46 \\
\hline Do not Know & 98 & 24.29 \\
\hline Nothing & 56 & 12.60 \\
\hline Antibiotic creams & 19 & 7.20 \\
\hline Pyodine & 17 & 2.44 \\
\hline alcohol swabs & 12 & 2.19 \\
\hline Gentian violet & 9 & 1.54 \\
\hline Ghee/Oil & 1 & 1.16 \\
\hline chlorhexidine & & 0.13 \\
\hline
\end{tabular}

Antimicrobial use has been a predominant method (approx. $62 \%)$. The antimicrobials were methylated spirit (48.5\%) and others like pyodine, alcohol swabs, pyodine, gentian violet, antibiotic creams (containing Polymixin B, bacitracin zinc, fusidic acid, neomycin etc) in small percentages. Chlorhexidine gel as recommended by WHO was used by one participant. Thankfully, ghee or oil was used by only 9 females, and none used ash.

Though doctors have been the main source of knowledge in our study, who in combination with nurses and midwives, counselled about $70 \%$ of the participants. Most of the doctors were family physicians, who had prescribed the antibiotic. Relatives and grandmothers influenced $10 \%$ of the younger females, mostly having $1^{\text {st }}$ child.Cord clamp usage was $100 \%$.

We failed to find any significant correlation betweenthe method of cord care and socio-demographic characteristics.

\section{DISCUSSION}

After birth, the umbilical cord dries and shrivel in 5-7 days on average, ranging upto 15 days before falling off. The stump gets colonised with non-pathogenic bacteria. But omphalitis may happen if pathogenic bacteria invade the area, which if not treated promptly may cause sepsis and death. Staphylococcus aureus is the commonest bacteria, others are Staph. Epidermidis, group A and B Streptococci and rarely gram-negative bacteria, such as E. coli, Klebsiella pneumonia, pseudomonas and Aeromonas(10).

In comparison to previous studies, most of our participants were literate and resided in urban areas, so supposedly should be well educated about safe newborn care practices. But indiscriminate prescription by doctors and free over the counter availability of antibiotics and antimicrobial agents is worrisome. In some cases, families continued to use antibiotics for all babies, which have been prescribed for another child with omphalitis. Our number of participants using ghee or oil, or ash were minimal, which thankfully contrasts with previous local studies(11).

It is good that doctors and medical personnel were counselling most of the cases, the accuracy and safety of advice, however, needs to be improved inline with the latest guidelines. The role of relatives and grandmothers, though much less in our study, still impacts $10 \%$ of our participants.

Methylated spirit (denatured alcohol, containing ethanol and methanol), commonly called Spirit, is antibacterial and antifungal. It is the commonest agent used for cord care in our cohort, like results in other studies(12)(13). Its side effects include skin irritation, and prolonged cord separation time (10).

WHO recommended Chlorhexidine, which is potent against gram-positive organisms, especially staphylococci (14).Its use reduces omphalitis by $50 \%$, neonatal sepsis by $32 \%$ and neonatal mortality by $12 \%(15)(16)(17)(18)(19)$. There are some side effects such as dermatitis and neurotoxicity (14).

We need studies from rural areas, especially remote areas.

\section{CONCLUSION}

There is a wide gap in the actual practices and current guidelines. We should educate our doctors as well as the public about safe practices.

\section{REFERENCES}

1. Meshram II, Arlappa N, Balakrishna N, Mallikharjuna Rao K, Laxmaiah A Brahmam GNV. Trends in the prevalence of undernutrition, nutrient and food intake and predictors of undernutrition among under five year tribal children in India. Asia Pac J Clin Nutr. 2012;21(4):568-76.

2. Newborn care [Internet]. UNICEF DATA. [cited 2021 Jan 23]. Available from: https://data.unicef.org/topic/maternal-health/newborn-care/

3. Neonatal mortality [Internet]. UNICEF DATA. [cited 2021 Jan 25]. Available from: https://data.unicef.org/topic/child-survival/neonatal-mortality/

4. Esteves Mills J, Flynn E, Cumming O, Dreibelbis R. Determinants of clean birthing practices in low- and middle-income countries: a scoping review. BMC Public Health [Internet]. 2020 May 1 [cited 2021 Jan 24];20. Available from: https://www.ncbi.nlm.nih.gov/pmc/articles/PMC7195776/

5. Blencowe H, Cousens S, Mullany LC, Lee ACC, Kerber K, Wall S, et al Clean birth and postnatal care practices to reduce neonatal deaths from sepsis and tetanus: a systematic review and Delphi estimation of mortality effect. BMC Public Health. 2011 Apr 13;11 Suppl 3:S11.

6. Stewart D, Benitz W, Newborn C on FA. Umbilical Cord Care in the Newborn Infant. Pediatrics [Internet]. 2016 Sep 1 [cited 2021 Jan 24];138(3). Available

https://pediatrics.aappublications.org/content/138/3/e20162149

7. Fraser N, Davies BW, Cusack J. Neonatal omphalitis: a review of its serious complications. Acta Paediatr Oslo Nor 1992. 2006 May;95(5):519-22.

8. Chlorhexidine $7,1 \%$ digluconate $(\mathrm{CHX})$ aqueous solution or gel $(10 \mathrm{ml})$ : Reports of serious eye injury due to errors in administration [Internet]. [cited 2021 Jan 25]. Available from: https://www.who.int/news/item/28-08-2020chlorhexidine-7-1-digluconate-(chx)-aqueous-solution-or-gel-(10ml)-reportsof-serious-eye-injury-due-to-errors-in-administration

9. Gul S, Khalil R, Yousafzai MT, Shoukat F. Newborn care knowledge and practices among mothers attending pediatric outpatient clinic of a hospital in Karachi, Pakistan. Int J Health Sci. 2014 Apr;8(2):167-75.

10. Al-Shehri H. The Use of Alcohol versus Dry Care for the Umbilical Cord in Newborns: A Systematic Review and Meta-analysis of Randomized and Non-randomized Studies. Cureus [Internet]. [cited 2021 Jan 24];11(7). Available from: https://www.ncbi.nlm.nih.gov/pmc/articles/PMC6728785/

11. Pirzada S, Anwar ${ }^{*}$, Hasnain F, Farooq A, lqbal N, Noor RG and F. Cord Care Practices in Newborns - Fresh Look into Old Problem. Acta Sci Paediatr. 2021 Nov 17:4(12):00-00.

12. Afolaranmi TO, Hassan ZI, Akinyemi OO, Sule SS, Malete MU, Choji CP, et al. Cord Care Practices: A Perspective of Contemporary African Setting Front Public Health [Internet]. 2018 [cited 2021 Jan 24];6. Available from: https://www.frontiersin.org/articles/10.3389/fpubh.2018.00010/full\#B7

13. Chingle MP, Alubo SJ, Entonu PI, Ayuba JB. Knowledge and Practice of Healthy Cord Care Among Mothers In Angwanrukuba [Internet]. Rochester, NY: Social Science Research Network; 2019 May [cited 2021 Jan 24]. Report No.: ID $3395496 . \quad$ Available from: https://papers.ssrn.com/abstract $=3395496$

14. Sathiyamurthy S, Banerjee J, Godambe SV. Antiseptic use in the neonata intensive care unit - a dilemma in clinical practice: An evidence based review. World J Clin Pediatr. 2016 May 8;5(2):159-71.

15. Sinha A, Sazawal S, Pradhan A, Ramji S, Opiyo N. Chlorhexidine skin or cord care for prevention of mortality and infections in neonates. Cochrane Database Syst Rev. 2015 Mar 5;(3):CD007835.

16. Shariff JA, Lee KC, Leyton A, Abdalal S. Neonatal mortality and topica application of chlorhexidine on umbilical cord stump: a meta-analysis of randomized control trials. Public Health. 2016 Oct;139:27-35.

17. Gelano TF, Bacha YD, Abate D. Effect of chlorhexidine cord application on prevention of neonatal sepsis in developing countries: Systematic review and meta-analysis. Int J Health Sci. 2019 Feb;13(1):40-51.

18. Karumbi J, Mulaku M, Aluvaala J, English M, Opiyo N. Topical Umbilical Cord Care for Prevention of Infection and Neonatal Mortality. Pediatr Infect Dis J. 2013 Jan;32(1):78-83.

19. Soofi S, Cousens S, Imdad A, Bhutto N, Ali N, Bhutta ZA. Topical application of chlorhexidine to neonatal umbilical cords for prevention of omphalitis and neonatal mortality in a rural district of Pakistan: a community-based, cluster-randomised trial. The Lancet. 2012 Mar 17;379(9820):1029-36. 